Review

\title{
Molecular Imaging and Therapy of Merkel Cell Carcinoma
}

\author{
Volkan Beylergil $^{1, *}$ and Jorge A. Carrasquillo ${ }^{1,2}$ \\ 1 Molecular and Imaging Therapy Service, Department of Radiology Box 77, \\ Memorial Sloan-Kettering Cancer Center 1275 York Ave, New York, NY 10065, USA; \\ E-mail:beylergv@mskcc.org \\ 2 Department of Radiology, Weill Cornell Medical Center, New York, NY 10065, USA \\ * Author to whom correspondence should be addressed; E-Mail: beylergv@mskcc.org; \\ Tel.: +1-212-639-5313; Fax: +1-212-639-8045.
}

Received: 28 February 2014; in revised form: 8 April 2014 / Accepted: 14 April 2014 /

Published: 29 April 2014

\begin{abstract}
Several molecular imaging modalities have been evaluated in the management of Merkel cell carcinoma (MCC), a rare and aggressive tumor with a high tendency to metastasize. Continuous progress in the field of molecular imaging might improve management in these patients. The authors review the current modalities and their impact on MCC in this brief review article.
\end{abstract}

Keywords: Merkel cell carcinoma; FDG; PET/CT; fluorodeoxyglucose; molecular; imaging; sentinel node

\section{Introduction}

Merkel cell carcinoma (MCC) is a rare malignant tumor first described in 1972 by Toker [1]. MCC is an aggressive tumor of the skin that arises from neuroendocrine cells within the basal layer of the epidermis, affecting mainly sun-exposed areas with high tendency for metastatic disease [2]. Although the exact etiology remains unknown, viral carcinogenesis is suggested. Approximately $80 \%$ of tumors have Merkel cell polyomavirus and MCC might coexist with other skin or hematopoietic malignancies [3]. Typical sites of metastatic disease include lymph nodes, skin, lung, CNS and bone [4] and prognosis is worse than melanoma [5]. Treatment of the primary consists of surgical resection for the purpose of cure or for improved regional control. MCC is considered radiosensitive and radiation therapy plays a role in almost every clinical scenario. Radiotherapy may be used for definitive (curative) or adjuvant 
treatment of primary tumor, and definitive, adjuvant and prophylactic treatment of lymph node basin. For a complete discussion of the role of radiation treatment in MCC, readers are strongly encouraged to read a recent review article [6].

Given that, pre-treatment staging is an independent predictor of survival [7] nodal sampling is frequently performed to avoid the need for total neck dissection [8]. Because of significant metastatic potential and frequent reoccurrence patients often undergo computed tomography (CT scan) for evaluation of extent of disease and surveillance [9]. Nonetheless, CT cannot differentiate tumor in nodes smaller than $1 \mathrm{~cm}$ and detection rate of $20 \%$ for nodal disease has been described at initial staging [10]. Given the limitations of anatomical imaging modalities such as CT, the use of molecular and hybrid imaging plays an important role in the management of MCC.

\section{Molecular Imaging and Therapy of Merkel Cell Carcinoma}

\subsection{Potential Agents}

Various radiolabeled compounds that take advantage of molecular pathways that are present in neuroendocrine tumor have been evaluated in MCC [11]. MIBG is a radiolabeled analogue of guanethidine that enter cells via NET transporter and is either stored in the cytoplasm or in secretory granules. Von Moll et al. studied MIBG avidity of different neuroendocrine tumors and reported one case of MCC with ${ }^{131}$ I-MIBG uptake [12]. In another study, one of two cases of MCC was detected on ${ }^{131}$ I-MIBG scan [13]. More recently, ${ }^{123}$ I-MIBG is used rather than ${ }^{131}$ I-MIBG because of more favorable imaging characteristics. A case report of ${ }^{123} \mathrm{I}-\mathrm{MIBG}$ imaging of $\mathrm{MCC}$ has appeared [14]. Given the limited studies no role can be advocated for MIBG imaging.

A limited number of reports using somatostatin receptor scintigraphy (SRS) in MCC have appeared in the literature. The potential utility of this technique is based on the presence of somatostatin receptor type 2, with one report demonstrating presence of this receptor by RT-PCR in nine of 10 patients examined [15]. Kwekkeboom studied five patients with CT and SRS and detected uptake in four of five cases with both, but additional lesions were positive with SRS compared to CT [16]. In contrast, Durani et al. studied 11 patients with SRS and showed positive uptake in four of seven patients whereas false negative or false positive were seen in five of 11 [17]. In a larger series Guitera-Rovel evaluated 20 patients with Merkel cell tumor with SRS [18]. Their sensitivity was $78 \%$ and specificity was $95 \%$. Overall four of the five primary and six of eight lymph node metastasis, two of three thoracic metastases and zero out of two liver metastases and none of the metastatic skin lesion in two patients were visualized [18]. In a group of six patients with MCC SRS detected all three patients with active disease [19]. In these reports SRS typically did [20] not add additional information beyond conventional imaging to recommend it routinely [7,18]. A head to head comparison of SRS to FDG in a group of nine patients showed that FDG outperformed SRS with no SRS positive FDG negative lesions, implying SRS is suboptimal for imaging MCC [21] (Figures 1-4). Nonetheless a potential role for SRS is as a theranostic reagent for selection of patients who may be candidates for ${ }^{90} \mathrm{Y} /{ }^{177} \mathrm{Lu}$ somatostatin analog receptor directed therapy $[22,23]$. 
Figure 1. FDG PET/CT shows a focal milimetric focus not visualized on octreotide scan a day prior to $\mathrm{PET} / \mathrm{CT}$ scan.

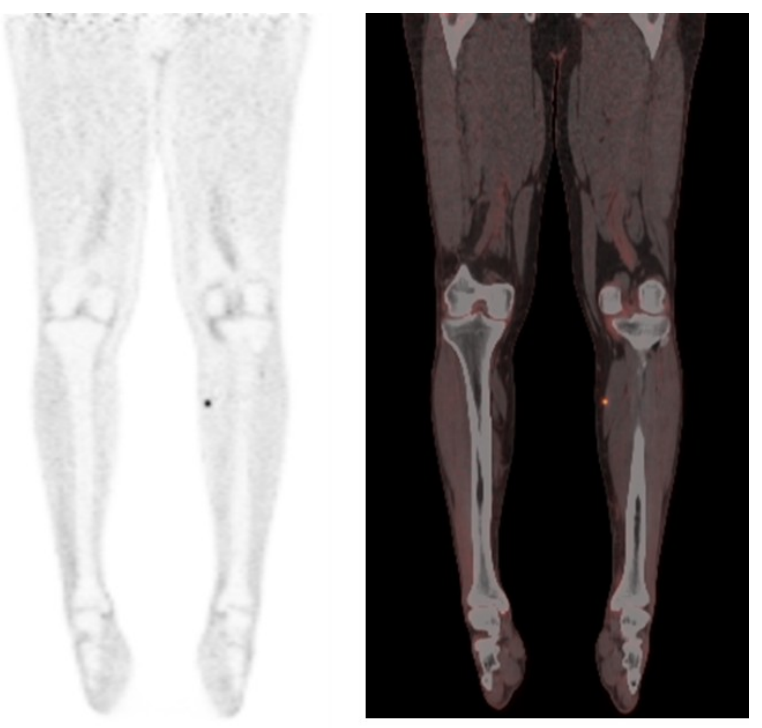

Figure 2. FDG PET/CT showing left inguinal node metastases in a patient with Merkel cell carcinoma.
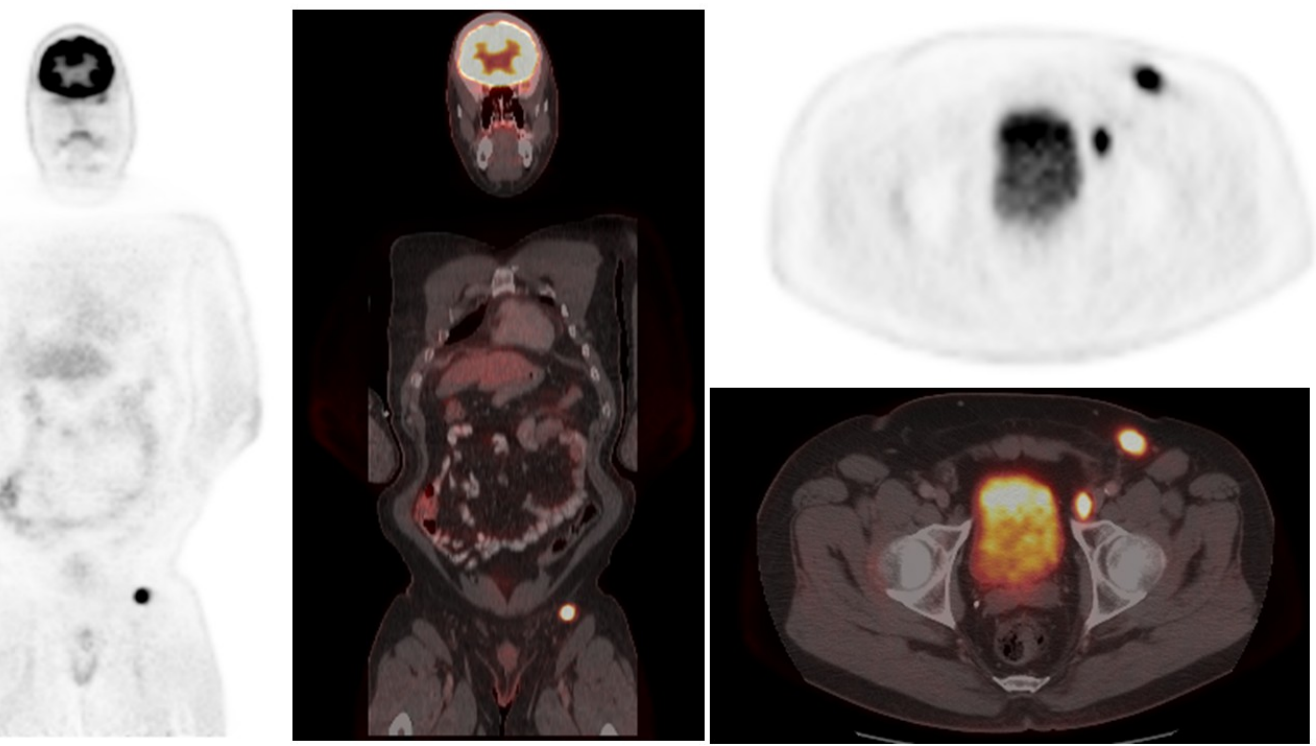
Figure 3. A series of axial fused PET/CT images showing gradual progress in liver metastasis from Merkel cell carcinoma.

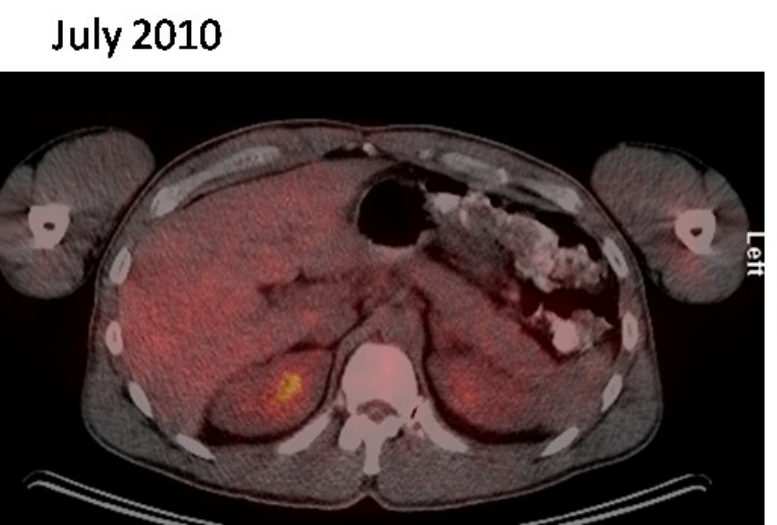

May 2011

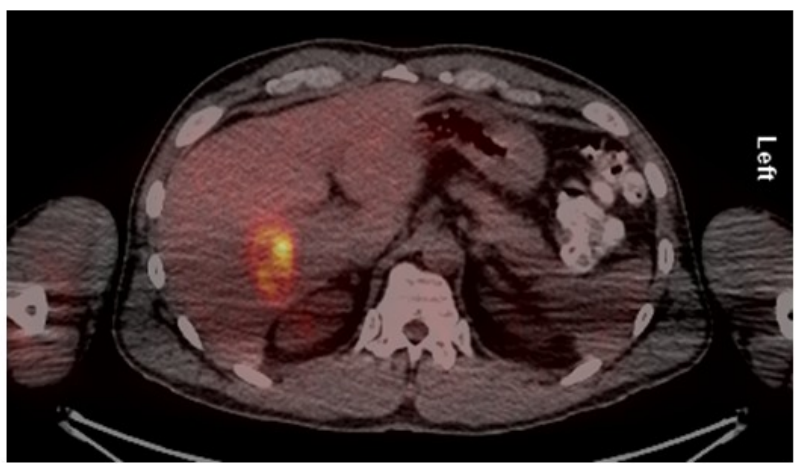

January 2011

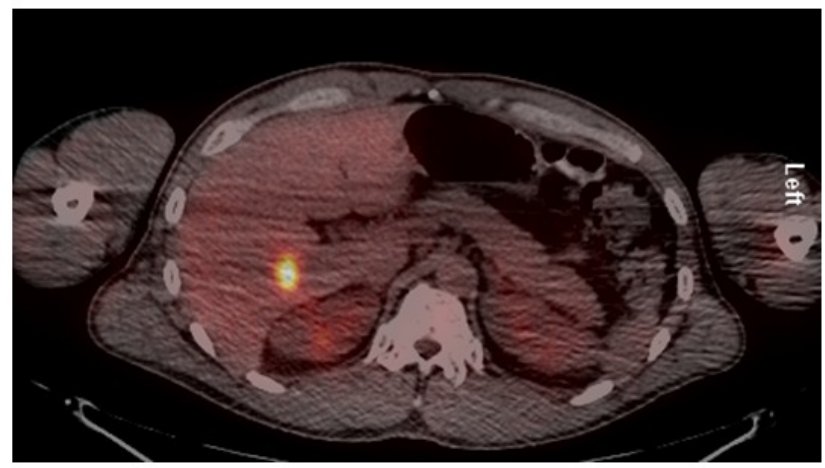

August 2011

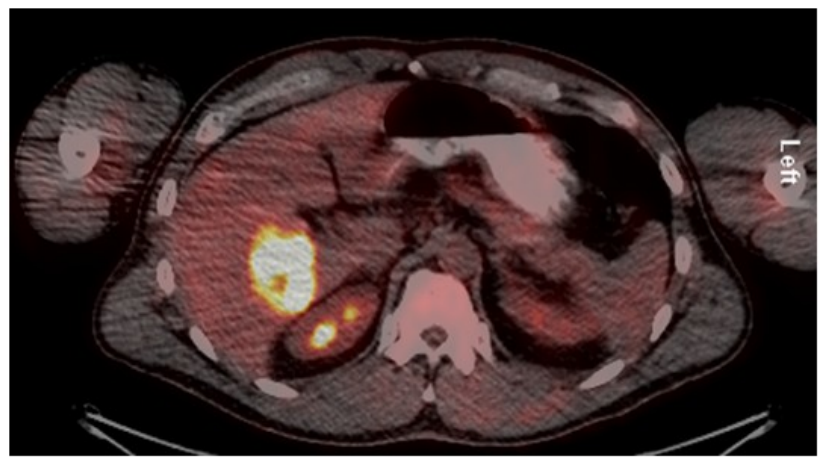

Figure 4. Subtle liver metastasis in a Merkel cell carcinoma patient that is not appreciable on octreotide scan. Right axillary nodal metastasis, on the other hand is visible on both studies.
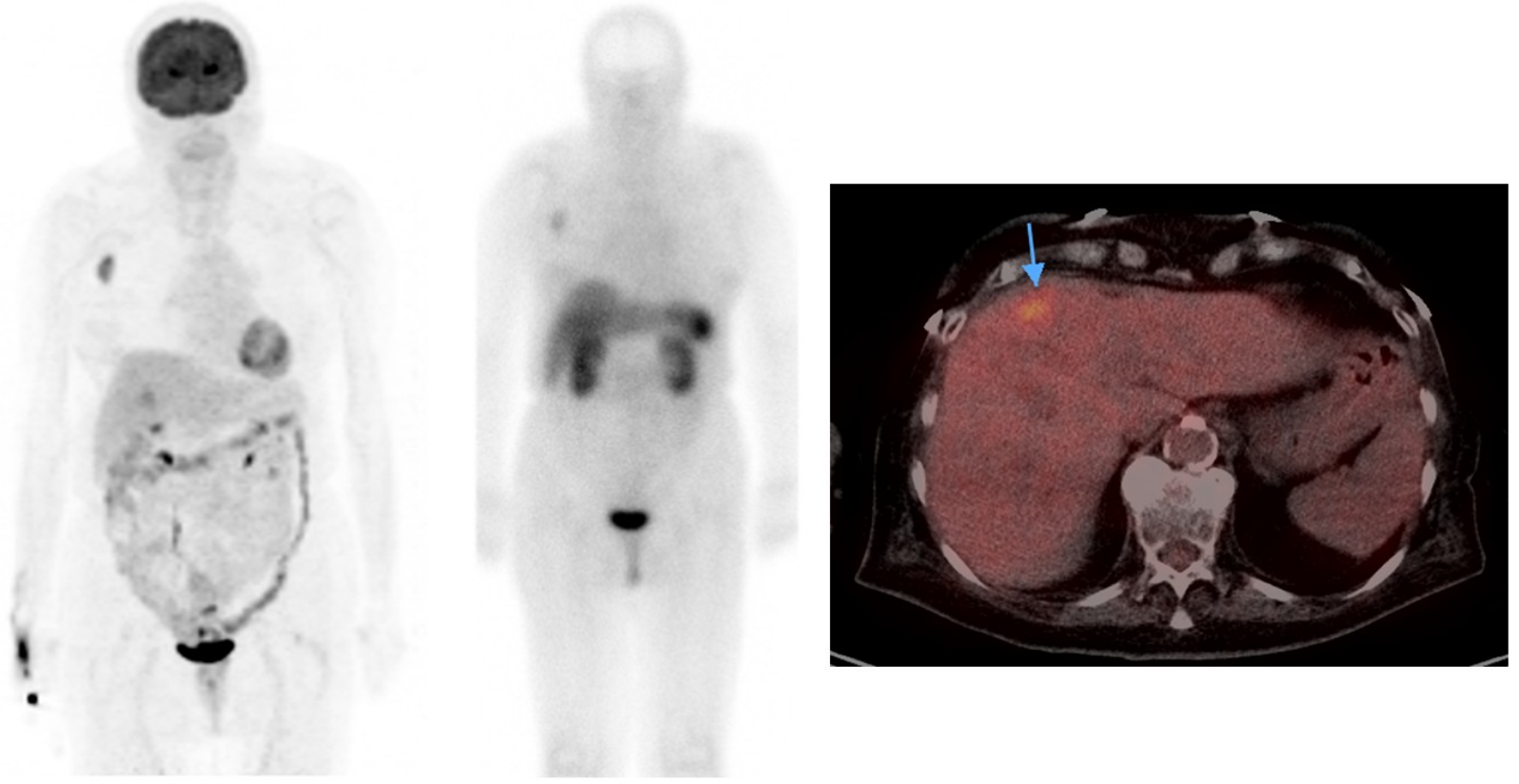

The use of ${ }^{68} \mathrm{Ga}$ labeled somatostatin analogs such as DOTATOC, DOTATATE and DOTANOC has been shown to be far superior to that of ${ }^{111}$ In pentetretotide SRS. Preliminary case reports have 
indicated that ${ }^{67} \mathrm{Ga}$-DOTATATE can localize well in MCC, with one case showing better localization than FDG [22,24,25]. In order to determine if there is any role for these new ${ }^{68} \mathrm{Ga}$ PET tracers additional studies need to be performed evaluating their utility in MCC.

Fluorodopa is an ${ }^{18} \mathrm{~F}$ labeled amino acid analog that enter the cell through LAT transporters and has been shown useful in a variety of neuroendocrine tumors [11]. There have been preliminary reports of ${ }^{18} \mathrm{~F}$-DOPA in small number of MCC $[19,26]$. Although the limited number of patients prevents general conclusion, it appears that it has less contrast and sensitivity than FDG for MCC.

\section{2. ${ }^{18}$ F-FDG PET/CT in Merkel Cell Carcinoma}

Broader experience is available with FDG (Table 1). Overall FDG has had good sensitivity for detecting nodal or metastatic disease. The intensity of uptake is high with mean $\mathrm{SUV}_{\max }$ values ranging from $\sim 4$ to 13.6 [27-29] The sensitivity for tumor detection is high, ranging from $79 \%-94 \%$ with very high specificity, $>96 \%$ (Table 1). Interestingly the Ki-67 index is elevated, with a mean value of $50 \%$ which in other neuroendocrine tumor has been associated with increased FDG uptake [20,27]. In one report comprising 21 patients, FDG results changed staging in 33\% of the patients with MCC and altered management in $43 \%$ of the patients [28]. Hawryluk et al. retrospectively reviewed 270 FDG PET/CT studies performed in 97 patients and concluded that FDG resulted in upstaging in $16 \%$ of patients [30] similarly a retrospective single center study reported changes in tumor status in $20 \%$ of patients [31]. Recently, Siva et al. showed that FDG played a very important role in the risk stratification and management of MCC patients [32]. In their large series involving prospective analysis of 102 patients, they observed that PET changed the management plan in $37 \%$ of patients which was in parallel with prior studies in smaller series and somewhat more than $15 \%$ reported by Ibrahim et al. [31]. They also showed that presence of nodal disease on PET and the presence of any metabolically active disease on PET were associated with decreased overall and progression free survival. Overall, MCC lesions were highly FDG avid in this series, similar to previous reports with lower number of patients. They reported a mean SUV max of 10.3, however there was no association between SUV values and prognosis.

Table 1. Sensitivity and specificity of FDG PET/CT vs. somatostatin receptor scintigraphy.

\begin{tabular}{ccccc}
\hline Author (number of patients) & SRS sensitivity & SRS specificity & FDG sensitivity & FDG specificity \\
\hline$[18] n=20$ & $78 \%$ & $96 \%$ & NA & NA \\
{$[28] n=21$} & NA & NA & $94 \%$ & $100 \%$ \\
{$[27] n=11$} & NA & NA & $92 \%$ & $100 \%$ \\
{$[19] n=16$} & NA & NA & $85.7 \%$ & $96.2 \%$ \\
\hline
\end{tabular}

A recent meta-analysis on diagnostic performance of FDG PET/CT involving ten studies with a total number of 329 patients, reported sensitivity of $90 \%$ and specificity of $98 \%$ [33]. A prospective trial sponsored by Trans-Tasman Radiation Oncology Group (TROG) is currently accruing patients and will help further clarify the role of PET/CT in patients with MCC (NCT01013779).

There are no head to head comparisons of functional imaging modalities nor are there prospective comparisons of functional and anatomical imaging. Colgan et al. reported in a retrospective study that FDG is far more sensitive than CT in assessing nodal involvement in patients with MCC [34]. 
Although there are no guidelines on scan coverage, head to toe imaging appears to be appropriate to visualize possible metastases in the distal parts of the skeleton and cranium [35].

In summary given the high incidence of regional and metastatic disease and their effect on prognosis, and the high sensitivity of FDG for MCC it appears to have a role in the evaluation of these patients when regional and metastatic disease is suspected, although well designed prospective studies have not been performed.

\section{Sentinel Node Biopsy in Merkel Cell Carcinoma}

Sentinel lymph node is the first node or group of nodes draining a tumoral mass. SLN concept is not new and successful localization of sentinel node with a gamma probe dates back to 1993 [36]. SLN has been widely used for various malignancies including breast cancer, melanoma, gynecologic and penile cancers.

The role of sentinel node biopsy (SLNB) in MCC is not as well established as in early stage breast cancer or melanoma, partially owing to lack of prospective studies due to the fact that MCC is a very rare skin malignancy. It is still unclear whether a positive SLNB in MCC has therapeutic and prognostic implications. Gupta et al. reported on their institutional experience combined with a meta-analysis of the existing cases in the literature [10]. They concluded that the recurrence rate was three times higher in the SLNB positive patients compared with SLNB negative group. SLNB upstaged about one third of patients who would have been categorized as stage I based on clinical criteria. They recommended routine use of SLNB for MCC patients. Largest single center study in the literature performed by investigators from the Memorial Sloan-Kettering Cancer Center reported 29\% SLNB positivity in clinically node negative patients. In their series comprising 153 patients, there was no statistically significant association between SLNB status and recurrence and survival [37]. Interestingly, 26\% of patients with primary tumors measuring $1 \mathrm{~cm}$ or less had positive SLNB. They concluded that presence of lymphovascular invasion is a strong predictor of positive SLNB. On the other hand, Schwartz et al. identified clinical size, greatest histologic dimension, tumor thickness and mitotic rate as predictors of SLNB positivity [38]. In a group of 93 patients, $23.8 \%$ of patients had SLNB positivity despite having a small clinical primary tumor measuring $1 \mathrm{~cm}$ or less. Therefore, both groups have recommended routine SLNB for MCC patients without clinical evidence of lymph node metastases. Although Stokes et al. recommended SLNB only for patients with tumors $1 \mathrm{~cm}$ or greater [39], based on above reviews tumor diameter is not a reliable criteria to preclude SLNB.(Figure 5) Sattler et al. demonstrated increased overall survival benefit of 211 months in patients who underwent SLNB compared to 72 months without SLNB procedure. Kachare et al. [40] recently analyzed 1193 patients in the Surveillance, Epidemiology, and End Results (SEER) registry and found that SLNB negativity was associated with improved MCC-specific survival (84.5\% vs. 64.6\%). However, better outcome in the SLNB positive group might be confounded by different management strategies in this group. The value of SLNB might also differ according to body region. For example, Fritsch et al. reported an analysis of 721 patients with head and neck MCC in the SEER database where they could not show a survival advantage in SLNB negative group [41]. 
Figure 5. Sentinel node scintigraphy in a patient with MCC of the left forearm.

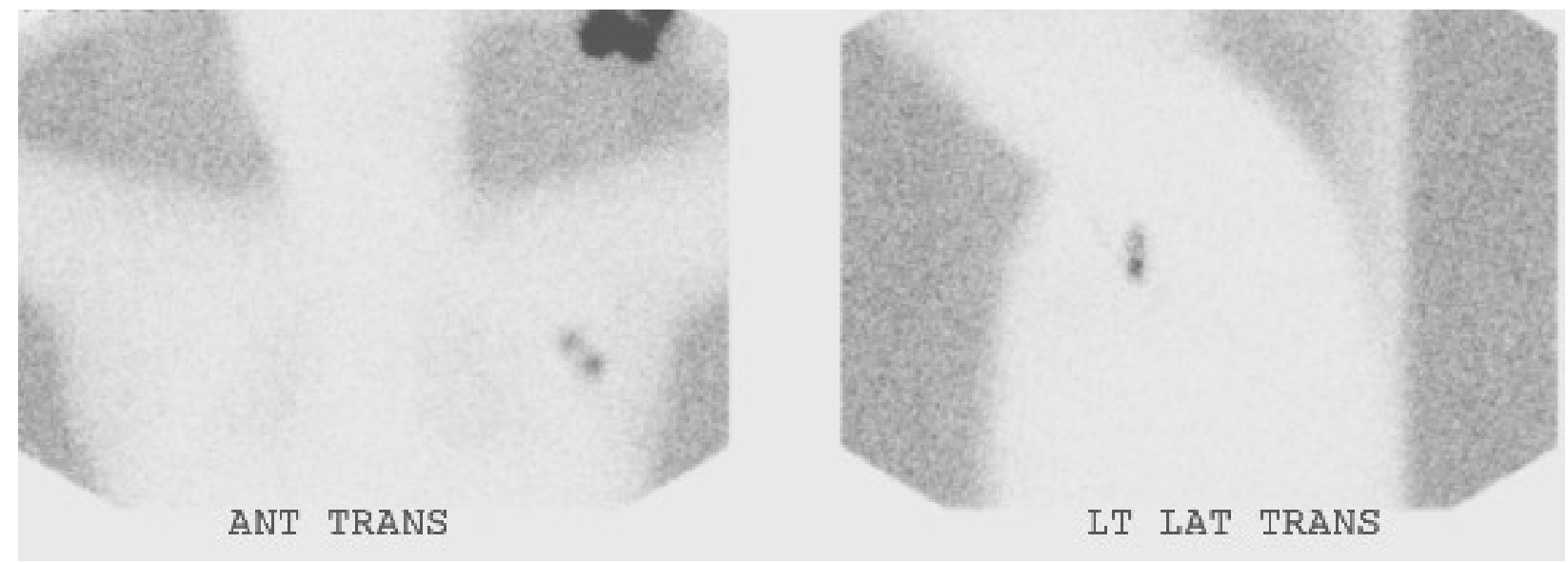

False negative rate of SLNB in MCC tend to be higher than other cancers. Howle et al. reported a false negative rate of $20 \%$ and more recently Shibayama et al. reported a false negative rate of $12.9 \%$ in a group of 403 patients [42]. However, false negative rate is much lower for melanoma [43].

Although controversies exist regarding the impact of SLNB in the management of MCC, NCCN guidelines recommend SLN biopsy for all clinically N0 patients before wide surgical excision [44]. Because of resolution issues FDG is less sensitive for picking up small nodal disease than SLN [30].

The combination of blue dye, gamma probe and lymphoscintigraphy is the most accurate approach for successful localization. The rate of non-visualization is low in the literature. Schwartz et al. reported non-visualization in 4\% of cases [38]. However, Maza et al. and Fields et al. were able to identify at least one sentinel node in all of their patients [8,37]. New techniques such as SPECT/CT and intraoperative cameras might further increase the sentinel node detection rate and help in complicated cases where primary tumor is close to the drainage site. Recently, there has been interest in combining new radiopharmaceuticals such as Zr-89 nanoalbumin with PET/CT [45].

\section{Conclusions}

In summary, F-18 FDG PET/CT stands out as the best molecular imaging method for Merkel cell carcinoma. Well designed prospective studies are needed to elucidate the role of SLNB procedure in MCC.

\section{Conflicts of Interest}

The authors declare no conflict of interest.

\section{References}

1. Toker, C. Trabecular carcinoma of skin. Arch. Dermatol. 1972, 105, 107-110.

2. Fields, R.C.; Busam, K.J.; Chou, J.F.; Panageas, K.S.; Pulitzer, M.P.; Allen, P.J.; Kraus, D.H.; Brady, M.S.; Coit, D.G. Five hundred patients with merkel cell carcinoma evaluated at a single institution. Ann. Surg. 2011, 254, 465-475. 
3. Tadmor, T.; Aviv, A.; Polliack, A. Merkel cell carcinoma, chronic lymphocytic leukemia and other lymphoproliferative disorders: An old bond with possible new viral ties. Ann. Oncol. 2011, 22, 250-256.

4. Medina-Franco, H.; Urist, M.M.; Fiveash, J.; Heslin, M.J.; Bland, K.I.; Beenken, S.W. Multimodality treatment of Merkel cell carcinoma: Case series and literature review of 1024 cases. Ann. Surg. Oncol. 2001, 8, 204-208.

5. Schwartz, J.L.; Bichakjian, C.K.; Lowe, L.; Griffith, K.A.; Frohm, M.L.; Fullen, D.R.; Hayman, J.A.; Lao, C.D.; Shah, K.S.; McLean, S.A.; et al. Clinicopathologic features of primary Merkel cell carcinoma: A detailed descriptive analysis of a large contemporary cohort. Dermatol. Surg. 2013, 39, 1009-1016.

6. Hruby, G.; Scolyer, R.A.; Thompson, J.F. The important role of radiation treatment in the management of Merkel cell carcinoma. Br. J. Dermatol. 2013, 169, 975-982.

7. Allen, P.J.; Bowne, W.B.; Jaques, D.P.; Brennan, M.F.; Busam, K.; Coit, D.G. Merkel cell carcinoma: Prognosis and treatment of patients from a single institution. J. Clin. Oncol. 2005, 23, 2300-2309.

8. Maza, S.; Trefzer, U.; Hofmann, M.; Schneider, S.; Voit, C.; Krossin, T.; Zander, A.; Audring, H.; Sterry, W.; Munz, D.L. Impact of sentinel lymph node biopsy in patients with Merkel cell carcinoma: Results of a prospective study and review of the literature. Eur. J. Nucl. Med. Mol. Imaging 2006, 33, 433-440.

9. Gollub, M.J.; Gruen, D.R.; Dershaw, D.D. Merkel cell carcinoma: CT findings in 12 patients. Am. J. Roentgenol. 1996, 167, 617-620.

10. Gupta, S.G.; Wang, L.C.; Penas, P.F.; Gellenthin, M.; Lee, S.J.; Nghiem, P. Sentinel lymph node biopsy for evaluation and treatment of patients with Merkel cell carcinoma-The dana-farber experience and meta-analysis of the literature. Arch. Dermatol. 2006, 142, 685-690.

11. Carrasquillo, J.A.; Chen, C.C. Molecular imaging of neuroendocrine tumors. Semin. Oncol. 2010, 37, 662-679.

12. Von Moll, L.; McEwan, A.J.; Shapiro, B.; Sisson, J.C.; Gross, M.D.; Lloyd, R.; Beals, E.; Beierwaltes, W.H.; Thompson, N.W. Iodine-131 MIBG scintigraphy of neuroendocrine tumors other than pheochromocytoma and neuroblastoma. J. Nucl. Med. 1987, 28, 979-988.

13. Castagnoli, A.; Biti, G.; de Cristofaro, M.T.; Ferri, P.; Magrini, S.M.; Papi, M.G.; Bianchi, S. Merkel cell carcinoma and iodine-131 metaiodobenzylguanidine scan. Eur. J. Nucl. Med. 1992, 19, 913-916.

14. Watanabe, N.; Shimizu, M.; Kageyama, M.; Kitagawa, K.; Hayasaka, S.; Seto, H. I-123-mibg spect of Merkel cell carcinoma. Br. J. Radiol. 1998, 71, 886-887.

15. Papotti, M.; Macri, L.; Pagani, A.; Aloi, F.; Bussolati, G. Quantitation of somatostatin receptor type 2 in neuroendocrine (Merkel cell) carcinoma of the skin by competitive RT-PCR. Endocr. Pathol. 1999, 10, 37-46.

16. Kwekkeboom, D.J.; Hoff, A.M.; Lamberts, S.W.J.; Oei, H.Y.; Krenning, E.P. Somatostatin analog scintigraphy - A simple and sensitive method for the in vivo visualization of Merkel cell tumors and their metastases. Arch. Dermatol. 1992, 128, 818-821.

17. Durani, B.K.; Klein, A.; Henze, M.; Haberkorn, U.; Hartschuh, W. Somatostatin analogue scintigraphy in Merkel cell tumours. Br. J. Dermatol. 2003, 148, 1135-1140. 
18. Guitera-Rovel, P.; Lumbroso, J.; Gautier-Gougis, M.S.; Spatz, A.; Mercier, S.; Margulis, A.; Mamelle, G.; Kolb, F.; Lartigau, E.; Avril, M.F. Indium-111 octreotide scintigraphy of Merkel cell carcinomas and their metastases. Ann. Oncol. 2001, 12, 807-811.

19. Peloschek, P.; Novotny, C.; Mueller-Mang, C.; Weber, M.; Sailer, J.; Dawid, M.; Czerny, C.; Dudczak, R.; Kletter, K.; Becherer, A. Diagnostic imaging in Merkel cell carcinoma: Lessons to learn from 16 cases with correlation of sonography, CT, MRI and PET. Eur. J. Radiol. 2010, 73, 317-323.

20. Abgral, R.; Leboulleux, S.; Deandreis, D.; Auperin, A.; Lumbroso, J.; Dromain, C.; Duvillard, P.; Elias, D.; de Baere, T.; Guigay, J.; et al. Performance of (18)fluorodeoxyglucose-positron emission tomography and somatostatin receptor scintigraphy for high Ki67 ( $\geq 10 \%)$ well-differentiated endocrine carcinoma staging. J. Clin. Endocrinol. Metab. 2011, 96, 665-671.

21. Lu, Y.; Fleming, S.E.; Fields, R.C.; Coit, D.G.; Carrasquillo, J.A. Comparison of 18F-FDG $\mathrm{PET} / \mathrm{CT}$ and 111In-pentetreotide scan for detection of Merkel cell carcinoma. Clin. Nucl. Med. 2012, 37, 759-762.

22. Meier, G.; Waldherr, C.; Herrmann, R.; Maecke, H.; Mueller-Brand, J.; Pless, M. Successful targeted radiotherapy with ${ }^{90} \mathrm{Y}$-DOTATOC in a patient with Merkel cell carcinoma-A case report. Oncology 2004, 66, 160-163.

23. Salavati, A.; Prasad, V.; Schneider, C.P.; Herbst, R.; Baum, R.P. Peptide receptor radionuclide therapy of Merkel cell carcinoma using (177)lutetium-labeled somatostatin analogs in combination with radiosensitizing chemotherapy: A potential novel treatment based on molecular pathology. Ann. Nucl. Med. 2012, 26, 365-369.

24. Epstude, M.; Tornquist, K.; Riklin, C.; di Lenardo, F.; Winterhalder, R.; Hug, U.; Strobel, K. Comparison of 18F-FDG PET/CT and 68Ga-DOTATATE PET/CT imaging in metastasized Merkel cell carcinoma. Clin. Nucl. Med. 2013, 38, 283-284.

25. Schmidt, M.C.; Uhrhan, K.; Markiefka, B.; Hasselbring, L.; Schlaak, M.; Cremer, B.; Kunze, S.; Baum, R.P.; Dietlein, M. 68Ga-DOTATATE PET-CT followed by peptide receptor radiotherapy in combination with capecitabine in two patients with Merkel cell carcinoma. Int. J. Clin. Exp. Med. 2012, 5, 363-366.

26. Talbot, J.N.; Kerrou, K.; Missoum, F.; Grahek, D.; Aide, N.; Lumbroso, J.; Montravers, F. 6-[F-18]Fluoro-L-DOPA positron emission tomography in the imaging of Merkel cell carcinoma: Preliminary report of three cases with 2-Deoxy-2-[F-18]fluoro-D-glucose positron emission tomography or pentetreotide-(111In) SPECT data. Mol. Imaging Biol. 2005, 7, 257-261.

27. Belhocine, T.; Pierard, G.E.; Fruhling, J.; Letesson, G.; Bolle, S.; Hustinx, R.; Dargent, J.L.; Flamen, P.; Rigo, P. Clinical added-value of $18 \mathrm{FDG}$ PET in neuroendocrine-Merkel cell carcinoma. Oncol. Rep. 2006, 16, 347-352.

28. Concannon, R.; Larcos, G.S.; Veness, M. The impact of ${ }^{18}$ F-FDG PET-CT scanning for staging and management of Merkel cell carcinoma: Results from Westmead Hospital, Sydney, Australia. J. Am. Acad. Dermatol. 2010, 62, 76-84.

29. Iagaru, A.; Quon, A.; McDougall, I.R.; Gambhir, S.S. Merkel cell carcinoma: Is there a role for 2-Deoxy-2-[f-18]fluoro-D-glucose-positron emission tomography/computed tomography? Mol. Imaging Biol. 2006, 8, 212-217. 
30. Hawryluk, E.B.; O’Regan, K.N.; Sheehy, N.; Guo, Y.; Dorosario, A.; Sakellis, C.G.; Jacene, H.A.; Wang, L.D.C. Positron emission tomography/computed tomography imaging in Merkel cell carcinoma: A study of 270 scans in 97 patients at the Dana-Farber/Brigham and Women's Cancer Center. J. Am. Acad. Dermatol. 2013, 68, 592-599.

31. Ibrahim, S.F.; Ahronowitz, I.; McCalmont, T.H.; Hernandez Pampaloni, M.; Ryan, J.L.; Yu, S.S. 18 F-Fluorodeoxyglucose positron emission tomography-computed tomography imaging in the management of Merkel cell carcinoma: A single-institution retrospective study. Dermatol. Surg. 2013, 39, 1323-1333.

32. Siva, S.; Byrne, K.; Seel, M.; Bressel, M.; Jacobs, D.; Callahan, J.; Laing, J.; MacManus, M.P.; Hicks, R.J. 18F-FDG PET provides high-impact and powerful prognostic stratification in the staging of Merkel cell carcinoma: A 15-year institutional experience. J. Nucl. Med. 2013, 54, 1223-1229.

33. Treglia, G.; Kakhki, V.R.; Giovanella, L.; Sadeghi, R. Diagnostic performance of fluorine-18-fluorodeoxyglucose positron emission tomography in patients with Merkel cell carcinoma: A systematic review and meta-analysis. Am. J. Clin. Dermatol. 2013, 14, 437-447.

34. Colgan, M.B.; Tarantola, T.I.; Weaver, A.L.; Wiseman, G.A.; Roenigk, R.K.; Brewer, J.D.; Otley, C.C. The predictive value of imaging studies in evaluating regional lymph node involvement in Merkel cell carcinoma. J. Am. Acad. Dermatol. 2012, 67, 1250-1256.

35. Golan, H.; Volkov, O.; Linchinsky, O.; Melloul, M. FDG-PET imaging in Merkel cell carcinoma-Value of head-to-toe scan. Nucl. Med. Rev. 2005, 8, 135-136.

36. Alex, J.C.; Krag, D.N. Gamma-probe guided localization of lymph-nodes. Surg. Oncol. 1993, 2, $137-143$.

37. Fields, R.C.; Busam, K.J.; Chou, J.F.; Panageas, K.S.; Pulitzer, M.P.; Kraus, D.H.; Brady, M.S.; Coit, D.G. Recurrence and survival in patients undergoing sentinel lymph node biopsy for Merkel cell carcinoma: Analysis of 153 patients from a single institution. Ann. Surg. Oncol. 2011, 18, 2529-2537.

38. Schwartz, J.L.; Griffith, K.A.; Lowe, L.; Wong, S.L.; McLean, S.A.; Fullen, D.R.; Lao, C.D.; Hayman, J.A.; Bradford, C.R.; Rees, R.S.; et al. Features predicting sentinel lymph node positivity in Merkel cell carcinoma. J. Clin. Oncol. 2011, 29, 1036-1041.

39. Stokes, J.B.; Graw, K.S.; Dengel, L.T.; Swenson, B.R.; Bauer, T.W.; Slingluff, C.L.; Ledesma, E.J. Patients with Merkel cell carcinoma tumors $\leq 1.0 \mathrm{~cm}$ in diameter are unlikely to harbor regional lymph node metastasis. J. Clin. Oncol. 2009, 27, 3772-3777.

40. Kachare, S.D.; Wong, J.H.; Vohra, N.A.; Zervos, E.E.; Fitzgerald, T.L. Sentinel lymph node biopsy is associated with improved survival in Merkel cell carcinoma. Ann. Surg. Oncol. 2014, $21,1624-1630$.

41. Fritsch, V.A.; Camp, E.R.; Lentsch, E.J. Sentinel lymph node status in Merkel cell carcinoma of the head and neck: Not a predictor of survival. Head Neck 2014, 36, 571-579.

42. Shibayama, Y.; Imafuku, S.; Takahashi, A.; Nakayama, J. Role of sentinel lymph node biopsy in patients with Merkel cell carcinoma: Statistical analysis of 403 reported cases. Int. J. Clin. Oncol. 2014, doi:10.1007/s10147-014-0685-3.

43. Li, L.X.; Scolyer, R.A.; Ka, V.S.; McKinnon, J.G.; Shaw, H.M.; McCarthy, S.W.; Thompson, J.F. Pathologic review of negative sentinel lymph nodes in melanoma patients with 
regional recurrence: A clinicopathologic study of 1152 patients undergoing sentinel lymph node biopsy. Am. J. Surg. Pathol. 2003, 27, 1197-1202.

44. Nccn Clinical Practice Guidelines In Oncology. Available online: http://www.nccn.org/ professionals/physician_gls/pdf/mcc.pdf (accessed on 3 December 2013).

45. Heuveling, D.A.; van Schie, A.; Vugts, D.J.; Hendrikse, N.H.; Yaqub, M.; Hoekstra, O.S.; Karagozoglu, K.H.; Leemans, C.R.; van Dongen, G.; de Bree, R. Pilot study on the feasibility of PET/CT lymphoscintigraphy with 89Zr-nanocolloidal albumin for sentinel node identification in oral cancer patients. J. Nucl. Med. 2013, 54, 585-589.

(C) 2014 by the authors; licensee MDPI, Basel, Switzerland. This article is an open access article distributed under the terms and conditions of the Creative Commons Attribution license (http://creativecommons.org/licenses/by/3.0/). 